\title{
Parálisis Facial post COVID - 19 y su rápida y efectiva respuesta al manejo con Medicina Bioreguladora
}

\author{
Andrea Valero ${ }^{1}$ \\ Autor para correspondencia: Andrea Valero, consultorioandreavalero@gmail.com \\ 1 consultorioandreavalero@gmail.com
}

\section{Resumen}

La infección por el virus del COVID - 19 ha tenido diferentes manifestaciones en quienes la han padecido, dentro de estas encontramos las asociadas al sistema nervioso tales como cefaleas, ageusia, anosmia, mialgias, encefalopatías y neuritis, las cuales son consecuencia del proceso inflamatorio que produce el virus el cual sugiere que utiliza la via axonal como mecanismo de transporte hacia el sistema nervioso.

En el presente caso clínico presenta una paciente quien el día 14 de infección por COVID 19 presenta episodio de parálisis facial derecha que no responde a manejo con esteroides ni antivirales asociado a temblores finos que compromete las cuatro extremidades y al ser tratada con medicina bioreguladora en biopuntura, sueroterapia y por via oral, muestra una respuesta favorable y rapida.

Palabras clave: case report, parálisis facial, COVID - 19

\section{Introducción}

El presente estudio muestra un caso de parálisis facial secundaria a infección por COVID - 19 y su respuesta rápida y efectiva al manejo con medicina de bioregulación fisiológica, lo cual evidencia la efectividad del tratamiento desde la modulación del proceso inflamatorio generado por el virus.

En estudios indexados se evidencian varios reportes de casos de parálisis facial de presentación aguda al curso de la enfermedad por COVID - 19 o de aparición tardía post infección (3), mostrando así que la parálisis facial es una de las manifestaciones del compromiso del sistema nervioso en el paciente con COVID - 19 (1), (2), (4)y según algunos de estos estudios se evidencia su aparición concomitante con la infección por el virus de Epstein Barr( 5)

Se presenta el caso de una paciente femenina de 42 años quien presenta parálisis facial el dia 14 de infección por COVID - 19 sin antecedentes de importancia quien súbitamente presenta desviación de la comisura oral en hemicara derecha con temblores finos en hemicuerpo derecho, limitación para el cierre palpebral del mismo lado, consulta a urgencias en donde toman TAC cerebral simple que reporta normal, paraclinicos normales, dan manejo con corticoide y antiviral, es dada de alta, no muestra mejoria y por el contrario aumentan sintomas y al tercer dia cursa con presencia de disartria 
y temblores finos en las 4 extremidades, cefalea intensa, por lo cual consulta nuevamente, toman nueva tomografia cerebral simple que nuevamente reporta normal, dan salida con analgésico y antinflamatorio oral, no mejoria y al dia siguiente acude a mi consulta en donde se inicia manejo con medicina de bioregulación fisiológica desde el enfoque inmunomodulador, y se observa mejoría de aproximadamente $20 \%$ del cuadro clínico desde las siguientes 24 horas de haber iniciado tratamiento hasta lograr un $100 \%$ de mejoria al dia 9 de tratamiento bioregulador.

En relación con el presente caso y su respuesta favorable con medicina de regulación fisiológica, se concluye que el enfoque desde la inmunomodulación y desde la regulación de la respuesta inflamatoria son efectivos en el tratamiento de la parálisis facial asociada a enfermedad por COVID -19 .

\section{Cronología}

2021-05-14 - Inician sintomas respiratorios altos dados por rinorrea, odinofagia, fiebre $38^{\circ}$, malestar general, mialgias. en trabajo ordena aislamiento por sintomas similares en compañeros de trabajo. se automedica con antigripales, acetaminofen, asa y azitromicina

2021-05-16 — Toman prueba PCR hisopado nasofaringeo para COVID - 19. persiste malestar general, fiebre promedio $38-38.5^{\circ}$. sigue igual medicación. Sus 3 hijos inician igual sintomatología.

2021-05-17 — Reporte prueba PCR positiva para COVID - 19 IPS expide incapacidad medica hasta completar 14 dias ( desde 14/05/21 hasta 27/05/21)

2021-05-27 - Mejoria de sintomas, solo manejo domiciliario. Ultimo dia de incapacidad Toma $2^{\circ}$ prueba PCR negativa

2021-05-28 - Al despertar, cefalea intensidad moderada a severa 8-9/10 y observa desviación de comisura labial hacia lado derecho, limitación para cierre ocular del mismo lado, y sensación de disestesias en hemicuerpo derecho 
2021-05-28 - Consulta a urgencias en donde toman TAC cerebral, reporte normal, hemograma normal, Cloro 104, Sodio 139, Potasio 4.7, creatinina 0.78. Dan diagnostico de parálisis facial periferica, inician manejo con dexametasona $8 \mathrm{mg}$ y dipirona $1 \mathrm{mg}$ intramusculares

dan salida con orden de incapacidad medica, acyclovir 200mg cada 8 horas y prednisolona 50mg dia

Cursa en $6^{\circ}$ dia de parálisis facial y no ha presentado mejoria de cuadro clinico, síntomas aumentan con aparición de disartria, parestesias que se hacen bilaterales. Y hay exacerbación de cefalea

Consulta nuevamente a urgencias en donde sospechan Accidente cerebrovascular, toman nuevo TAC cerebral y paraclinicos que reportan normales. confirman diagnostico de Parálisis facial y dan salida con naproxeno y acetaminofen

$\mathrm{Al}$ ingreso paciente algida, con temblores finos en las 4 extremidades, con desviación de comisura labial hacia lado recho, limitación para cierre palpebral derecho, disartrica, refiere cefalea 8/10 que no mejora con analgesico. antecedente de COVID $-19$

se inicia manejo con biopuntura en trayecto de nervio facial lado derecho y en region paravertebral cervical con: traumeel, spascupreel y neralgo injeel. se da salida con : engystol, traumeel y colocynthis por via oral 3 veces al dia mejoria de sintomas. se reintegra a su actividad laboral sin poder desempeñarlas por lo cual es llevada a consulta de medicina integrativa 


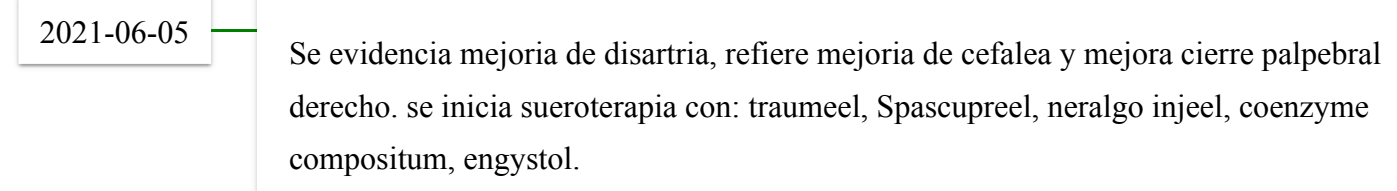

2021-06-09 _ asiste a 2 sesion de biopuntura con el esquema inicial, hay mejoria en $80 \%$ de sintomas clinicos, hay cierre palpebral, mejora desviacion de comisura labial, niega cefalea, no hay disartria, refiere disminución de temblores y parestesias.

2021-06-13 - Asiste a 2 sesión de sueroterapia con el esquema anterior, hay evidencia de mejoria completa del cuadro clinico, refiere que desde hace 6 dias ya viene laborando normalmente. sigue medicación oral. Se firman consentimientos para presentar caso.

\section{Descripción del caso}

Se trata de una paciente femenina de 42 años de edad, empleada de restaurante quien se desempeña como mesera, con antecedentes clinicos de trombosis venosa profunda bilateral hace 4 años, migraña cronica manejada sintomáticamente con analgésicos, G4P4A0V4, vive sola con sus 3 hijos menores.

Sufre contagio por COVID - 19 al igual que 8 de sus compañeros laborales, inicia cuadro clínico dado por fiebre de $38-38.5^{\circ}$, cefalea, malestar general, mialgias, congestión nasal, odinofagia, anosmia y ageusia, es enviada a cuarentena en casa, toman prueba PCR para covid- 19 con resultado positivo, inicia manejo en casa automedicada con azitromicina 500mg dia, asa $100 \mathrm{mg}$ dia, acetaminofen $500 \mathrm{mg}$ cada 8 horas y antigripales comerciales cada 12 horas. sus hijos inician igual sintomatologia, todos reciben mismo manejo en casa.

En el dia 14 de haber iniciado síntomas, al despertar evidencia desviación de hemicara derecha, temblores finos en hemicuerpo derecho y cefalea intensa por lo cual es llevada a urgencias en donde toman TAC cerebral simple y paraclínicos con reporte normal, dan manejo analgésico con dipirona y dexametasona intramusculares, salida con acyclovir 200mg cada 8 horas por 7 dias y prednisolona $5 \mathrm{mg}$ dia por 10 dias.

Cuatro días posteriores presenta empeoramiento de cuadro clínico dado por disartria, parestesias que comprometen las 4 extremidades y aumento de intensidad de cefalea. No hay mejoría de parálisis facial con manejo inicial. Consulta nuevamente a urgencias en donde sospechan Accidente Cerebrovascular, toman nuevo TAC cerebral simple que reporta normal, confirman diagnóstico inicial de Parálisis Facial, extienden incapacidad por 3 dias más y dan manejo analgésico con acetaminofén y naproxeno sin mostrar mejoria.

Posteriormente al reintegrarse a su actividad laboral no es posible desempeñarla normalmente por la persistencia de disartria y temblores, por lo cual consulta a medicina integrativa en donde ingresa 
paciente algida, con parálisis facial derecha severa grado V - VI de la escala de House Brackmann, disartrica, perdida de fuerza en extremidades y temblores finos de predominio en extremidades superiores bilaterales. Se inicia manejo con traumeel, spascupreel y neralgo injeel en técnica de biopuntura en trayecto de nervio facial de hemicara derecha y en region paravertebral cervical. se inicia engystol comprimidos, traumeel comprimidos y colocynthis homaccord gotas 3 veces al dia. se cita al dia siguiente para sueroterapia.

24 horas después se evidencia leve mejoría de disartria, con signos de parálisis facial derecha grado V de la escala de House Brackmann, con leve mejoría de cierre palpebral derecho, Se inicia sueroterapia con: coenzyme compositum, traumeel, neralgo injeel, spascupreel y engystol.

Asiste a control 4 dias después en donde se evidencia mejoría casi completa de cuadro clínico, con una parálisis facial grado II de la escala de House Brackmann, no hay disartria, refiere disminución de temblores, ya se reintegra a sus actividades laborales normalmente, hay cierre palpebral completo y mejoría de parálisis facial. Se repite esquema de biopuntura en trayecto de nervio facial y músculos paravertebrales cervicales.

Ultimo control a los 4 dias para sueroterapia con mejoria completa de toda la sintomatología. sin evidencia de parálisis facial correspondiente al grado I de la escala de Brackmann sigue medicación bioreguladora por via oral según indicaciones de la primera consulta.

\section{Diagnósticos}

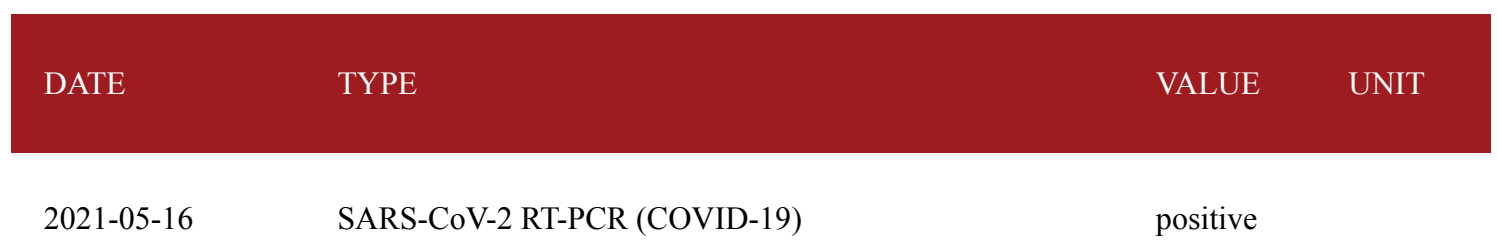

\section{Punto de vista del paciente}

"Yo consulto con la dra por secuelas de COVID, terminando el ultimo dia de aislamiento se me torcio la cara y la mayor parte del cuerpo con temblor que me generaba cansancio, la dra empieza su tratamiento y no hago alergia a ninguno, el cuerpo los toma bien y desde el primer dia empiezo a ver que muevo mejor la boca, puedo parpadear, siento mejor la cara y al tercer tratamiento veo $100 \%$ el cambio, puedo gesticular, hablar mejor, cerrar el ojo, percibo mejor los sabores. Estoy muy satisfecha y contenta con el tratamiento porque veo que fue eficaz y rápida la respuesta, mi cuerpo los acepto bien.

Yo no tenia conociemiento de la existencia de la biopuntura y veo que es rapida, eficaz y mi cuerpo la aceptaba rápido y facil sin ninguna reacción negativa, es muy buena la verdad y la recomiendo"

\section{Discusión}


Los resultados de este caso clínico a pesar de ser favorables y rápidos, constituyen un caso aislado, dado que en las publicaciones revisadas, no existe evidencia de manejo bioregulador para la parálisis facial asociada a la enfermedad por COVID - 19.

Sin embargo se pudieron revisar diferentes artículos en los cuales se hace referencia al compromiso neurológico asociado a la infección por el virus SARS - CoV- 2 y su posible diseminación via axonal dando un respuesta inflamatoria hacia la via del sistema nervioso generando asi una serie de manifestaciones clínicas dentro de las cuales esta la parálisis facial $(2,3)$

El virus genera una respuesta inflamatoria que puede progresar sistémica y comprometer los diferentes órganos y sistemas, por lo cual se podría concluir que quienes la padecen tienen disminuida esa capacidad de inmunomodulación frente al virus.

Los medicamentos bioreguladores nos permiten hacer un enfoque integral de tratamiento desde la inmunomodulación mejorando, tanto la respuesta inflamatoria del paciente como la modulación de la respuesta inmune frente al virus.

\section{Conclusión}

El virus SARS - CoV-2 puede atacar cualquier sistema del huésped generando una reacción inflamatoria que puede hacerse sistémica y producir diferente sintomatología dependiendo de los mecanismos de autoregulación que tenga el organismo del paciente para mediar este proceso, unos de estos son los asociados al sistema nervioso; que a pesar de su frecuencia de aparición en pacientes con COVID, para algunos colegas no son indicativos de compromiso del sistema nervioso, dentro estos tenemos: la cefalea, mialgias, ageusia y anosmia.

Diferentes estudios han proponen la hipótesis que el virus utiliza la via axonal como medio para invadir el sistema nervioso y generar asi los diferentes síntomas, es por esto que cada vez se han descrito mas complicaciones asociadas al sistema nervioso tanto en la fase aguda como en el cuadro post COVID. Una de estas están publicadas como : síndrome de Guillain Barre, polieuropatías, y la presentación de parálisis facial las cuales han recibido tratamientos convencionales con esteroides, antivirales tipo acyclovir y terapia física hasta por 27 dias (3).

En esta revisión de caso clínico se da manejo a una complicación por parálisis facial con medicina bioreguladora mostrando una respuesta rápida con una mejoria del 20\% desde las primeras 24 horas hasta lograr un $100 \%$ de mejora al dia 9 de tratamiento por lo cual se concluye que los medicamentos bioreguladores son efectivos y nos permiten hacer un enfoque integral de tratamiento desde la inmunomodulación mejorando, tanto la respuesta inflamatoria del paciente como la modulación de la respuesta inmune frente al virus y así mismo dar tratamiento a los síntomas asociados.

De acuerdo a lo anterior, el tratamiento bioregulador es efectivo y constituye una herramienta valiosa en el tratamiento de las diversas manifestaciones clínicas asociadas a la infección por COVID - 19

\section{Agradecimientos}


Agradezco a Dios porque haberme dado en la medicina el don de sanar y ayudar a mis semejantes.

A mis colegas que han sido mis docentes y que desde hace más de 15 años me enseñaron en la Medicina Bioreguladora una herramienta eficaz para el tratamiento de cualquier enfermedad por mayor desafio que pueda representar a la luz de la ciencia médica.

A mi maestra la Dra. Monica Name por inculcarme el hábito de escribir y reportar los diferentes casos clinicos manejados con medicina bioreguladora.

A Heel Colombia por fomentar e impulsar las publicaciones médicas, los concursos de casos clinicos y por estar siempre dispuesto a apoyarme en mis procesos de educación médica.

Al Dr. Baltazar Guerrero por su incansable labor educativa en las publicaciones de nuestros casos, por su paciencia y por estar dispuesto a responder nuestras dudas.

A mis pacientes por ser mis mejores docentes, por ponerme retos en cada uno de sus motivos de consulta, por escogerme como su médico y permitirme aprender de ellos. Por permitirme compartir la experiencia de sus tratamientos con mis demás colegas.

A mis hijos y a mi esposo, mis compañeros de vida por su paciencia, por permitirme compartir su tiempo con mis pacientes y mis horas de estudio.

\section{$\underline{\text { Referencias }}$}

1. Lima MA, Silva MTT, Soares CN, Coutinho R, Oliveira HS, Afonso L, Espíndola O, Leite AC, Araujo A. Peripheral facial nerve palsy associated with COVID-19. J Neurovirol. 2020 Dec;26(6):941-944. doi: 10.1007/s13365-020-00912-6. Epub 2020 Oct 2. PMID: 33006717

2. Codeluppi L, Venturelli F, Rossi J, Fasano A, Toschi G, Pacillo F, Cavallieri F, Giorgi Rossi P, Valzania F. Facial palsy during the COVID-19 pandemic. Behav. 2021 Jan;11(1):e01939. doi: 10.1002/brb3.1939. Epub 2020 Nov 7. PMID: 33159420

3. Casas E, Barbosa A, Rubio-García E, Cebrián J, Díaz-Pérez C, de la Fuente E, Vivancos J, López-Manzanares L.Isolated peripheral facial paralysis in a patient with COVID-19. Rev Neurol. 2020 Jul 1;71(1):40-41. doi: 10.33588/rn.7101.2020229. PMID: 32583415

4. Cabrera Muras A, Carmona-Abellán MM, Collía Fernández A, Uterga Valiente JM, Antón Méndez L, García-Moncó JC.Bilateral facial nerve palsy associated with COVID-19 and Epstein-Barr virus co-infection.Eur J Neurol. 2021 Jan;28(1):358-360. doi: 10.1111/ene.14561.PMID: 3299786

5. Islamoglu Y, Celik B, Kiris M. Facial paralysis as the only symptom of COVID-19: A prospective study.Am J Otolaryngol. 2021 Jul-Aug;42(4):102956. doi: 10.1016/j.amjoto.2021.102956. Epub 2021 Feb 10. PMID: 33592554

\section{Archivos adjuntos}


ESQRUEMA DE TRATAMIENTO PARALISIS FACIAL

\begin{tabular}{|c|c|c|c|c|}
\hline FECHA & TRATAMIENTO & ADMINISTRACION & SEERVICIO & Dosis \\
\hline \multirow[t]{4}{*}{$28 / 05 / 21$} & Dexametasona 8mg & \begin{tabular}{|l|} 
Intramuscular \\
\end{tabular} & Urgencias & Unica \\
\hline & Dipirona 1mg & Intramuscular & Urgencias & Unica \\
\hline & Prednisolona $5 \mathrm{mg} / \mathrm{dia}$ & Oral & Urgencias & 10 dias \\
\hline & Acyclovir $200 \mathrm{mg}$ cadash & Oral & Urgencias & 7 dias \\
\hline \multirow[t]{2}{*}{$31 / 06 / 21$} & Napraxeno 250me cada 8h & Oral & Urgencias & 3 dias \\
\hline & Acetaminofen 500mg cada $8 \mathrm{~h}$ & Oral & Urgencias & 3 dias \\
\hline \multirow[t]{6}{*}{$4 / 06 / 21$} & Spascupreel ampolla & Biopuntura & Consultario & Unica \\
\hline & Traumeel ampolla & Biopuntura & Consultario & Unica \\
\hline & Neralgo injeel ampolla & Biopuntura & Consultario & Unica \\
\hline & Engystal tabletas & Oral & Consultario & 1 cada 8 horas hasta terminar \\
\hline & Traumeel tabletas & Oral & Consultario & 1 cada 8 horas hasta terminar \\
\hline & Colocynthis Hamac.cord gotas & Oral & Consultario & 10 gotas cada 8 horas hasta terminar \\
\hline \multirow[t]{5}{*}{$5 / 06 / 21$} & Spascupreel ampolla & Sueroterapia & Consultario & Unica \\
\hline & Traumeel ampolla & Sueraterapia & Consultario & Unica \\
\hline & Engystal ampolla & Sueraterapia & Consultario & Unica \\
\hline & Coenzyme Compositum amp & Sueroterapia & Consultario & Unica \\
\hline & Neralgo injeel ampolla & Sueraterapia & Consultario & Unica \\
\hline \multirow[t]{5}{*}{$9 / 06 / 21$} & Coenzyme Compositum amp & Bippuntura & Consultario & Unica \\
\hline & Engystal ampolla & Biopuntura & Consultario & Unica \\
\hline & Neralgo injeel ampolla & Bippuntura & Consultario & Unica \\
\hline & Traumeel ampolla & Bippuntura & Consultorio & Unica \\
\hline & Spascupreel ampolla & Bippuntura & Consultario & Unica \\
\hline \multirow[t]{5}{*}{$13 / 06 / 21$} & Coenzyme Compositum amp & Biopuntura & Consultario & Unica \\
\hline & Engystol ampolla & Sueroterapia & Consultario & Uniça \\
\hline & Neralgo injeel ampolla & Sueraterapia & Consultario & Unica \\
\hline & Spascupreel ampolla & Sueraterapia & Consultario & Unica \\
\hline & Traumeel ampolla & Sueraterapia & Consultario & Unica \\
\hline
\end{tabular}

Resumen del esquema de tratamiento al momento de presentar la parálisis facial 


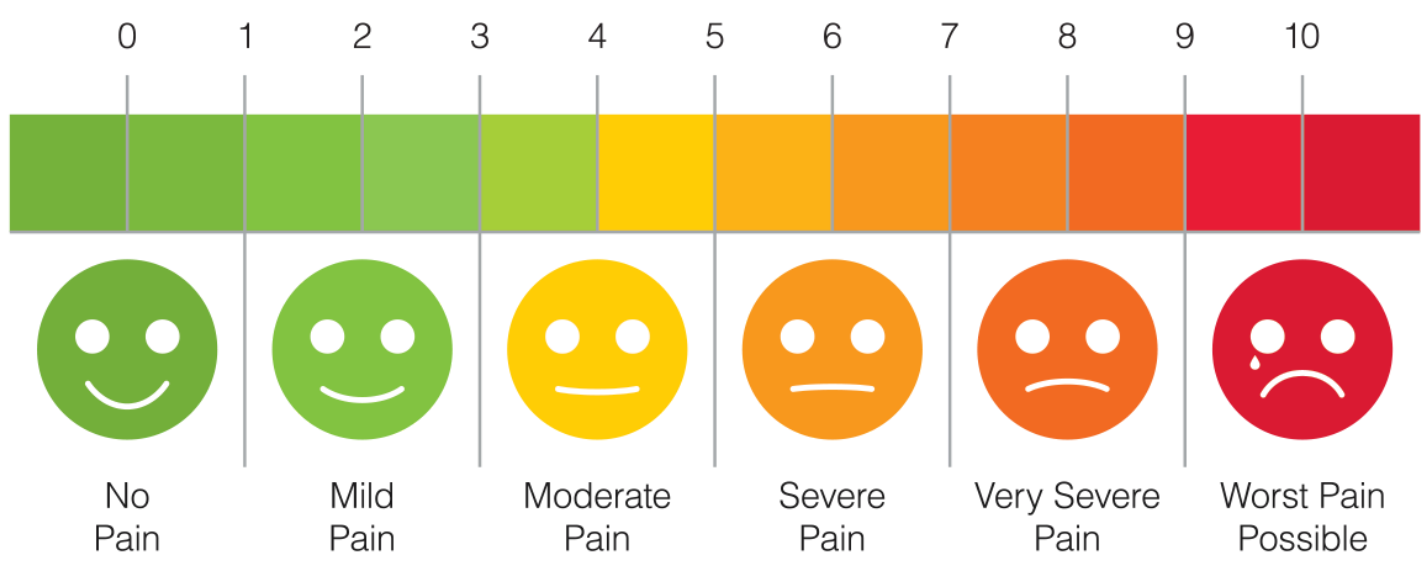

escala análoga del dolor en la que la paciente inicialmente referia dolor mayor a 8 (dolor severo ) y desde el primer tratamiento con medicina bioreguladora bajo a 0 ( sin dolor) 


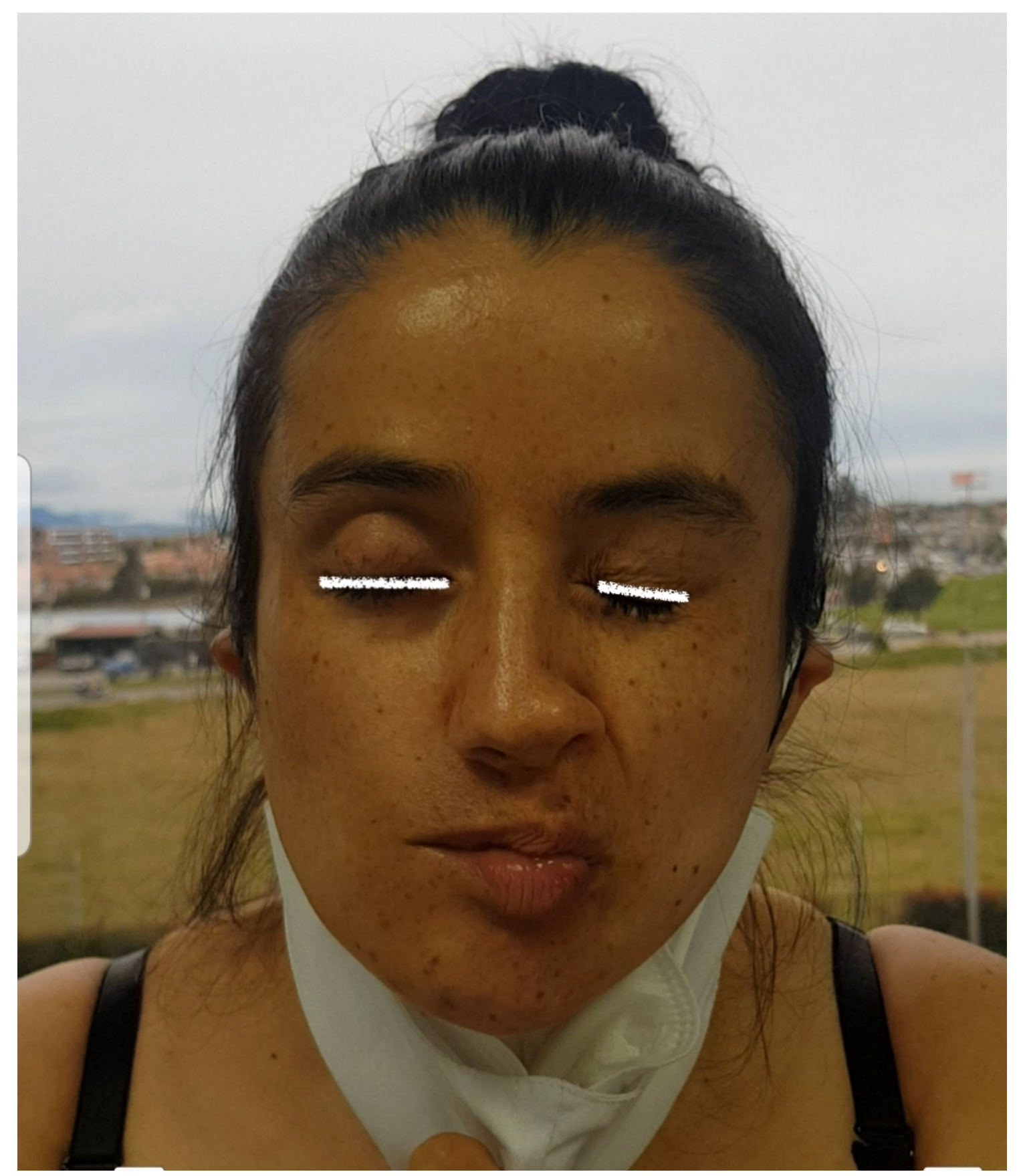

Foto inicial junio 04/21. Se observa claramente la asimetría por parálisis facial derecha Paralisis facial grado 5/6 escala de House Brackmann 


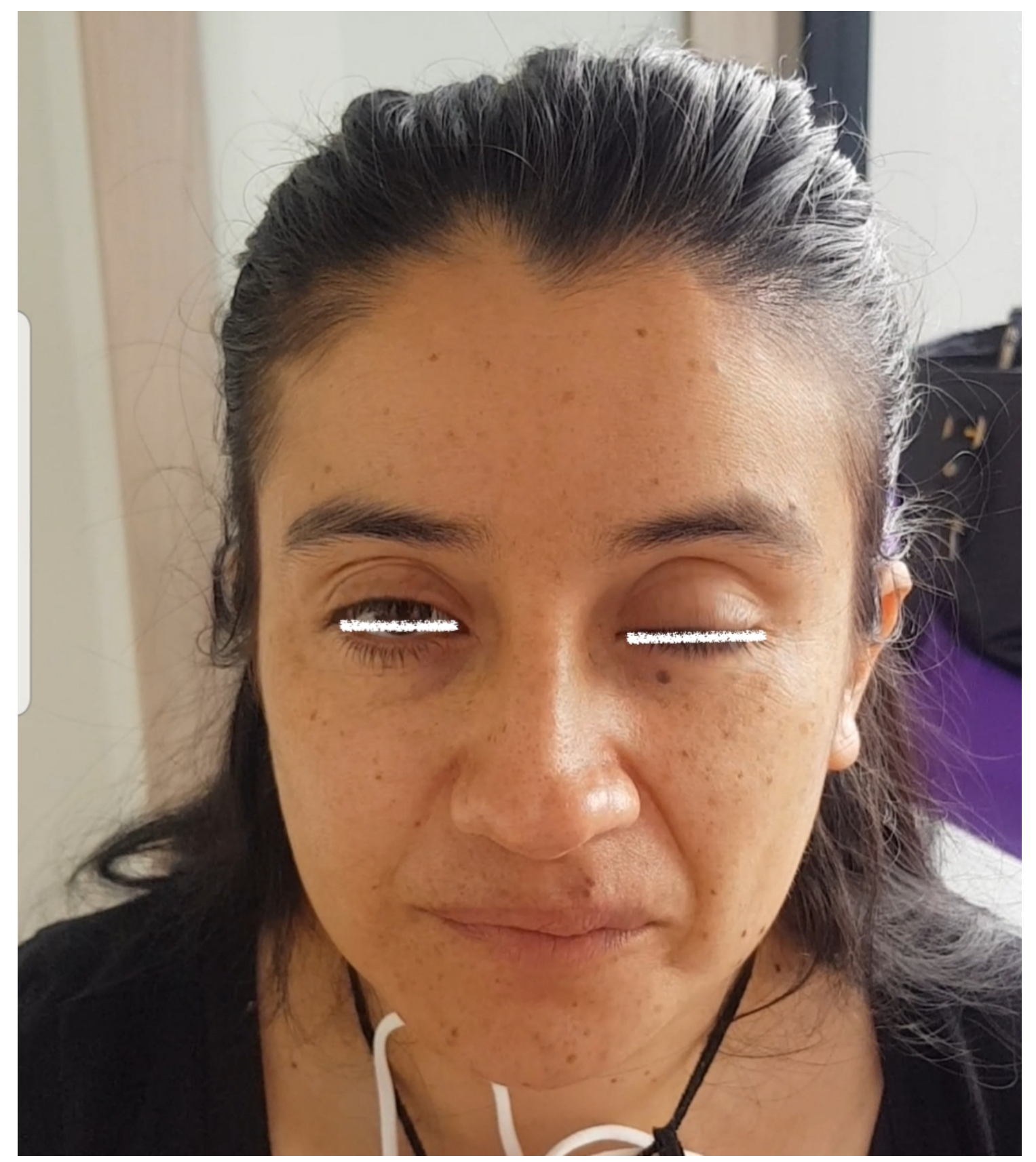

Forografia dia 2. Junio 05/2021. Se observa una leve mejoria de su asimetria, hay mejor cierre palpebral Parálisis facial grado 4/6 en escala de House Brackmann 


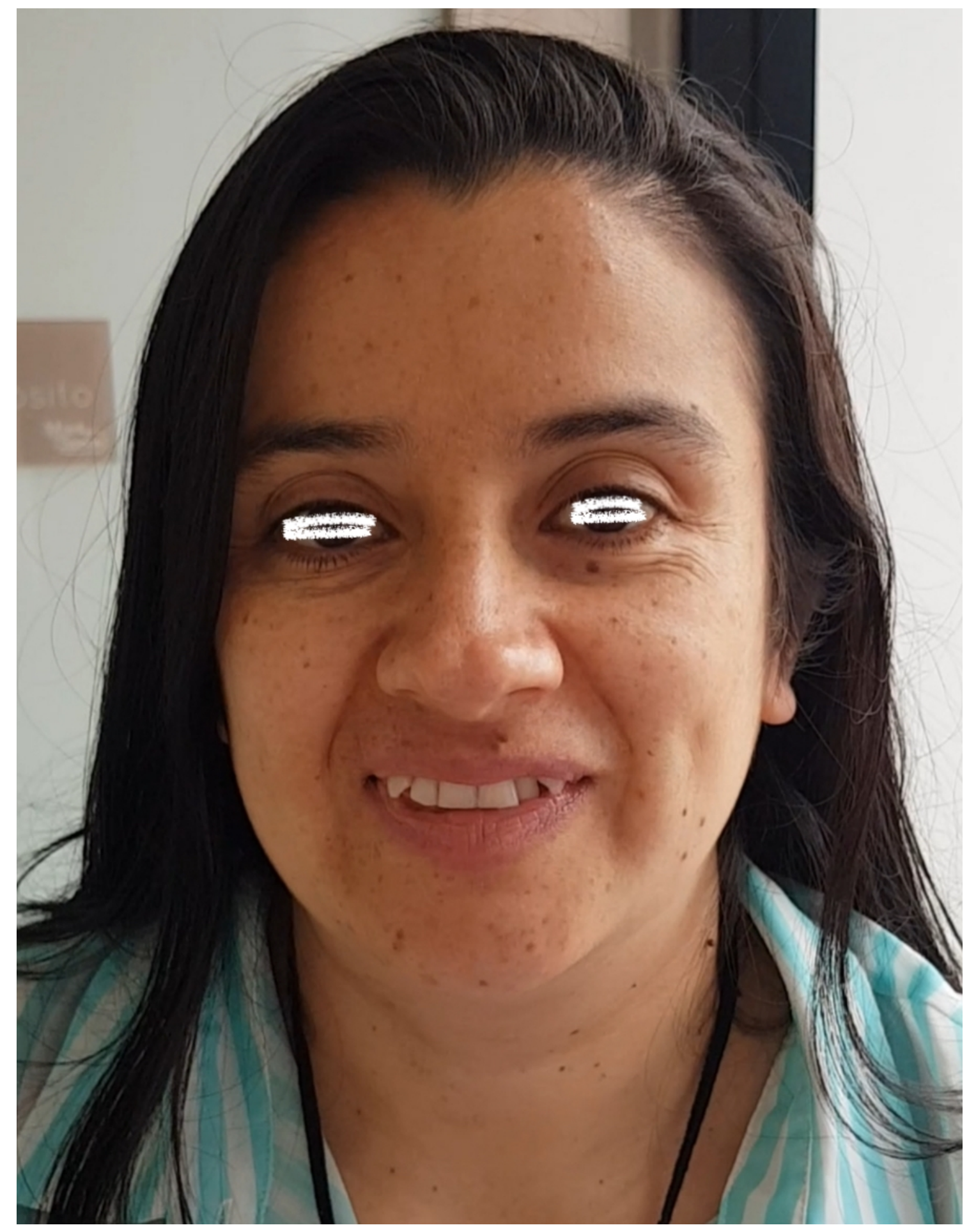

Fotografia 9 de junio. 5 dia de tratamiento, mejoria del 80\% de los signos de la parálisis facial Parálisis facial grado 2 - 3 / 6 en Escala de House Brackmann 


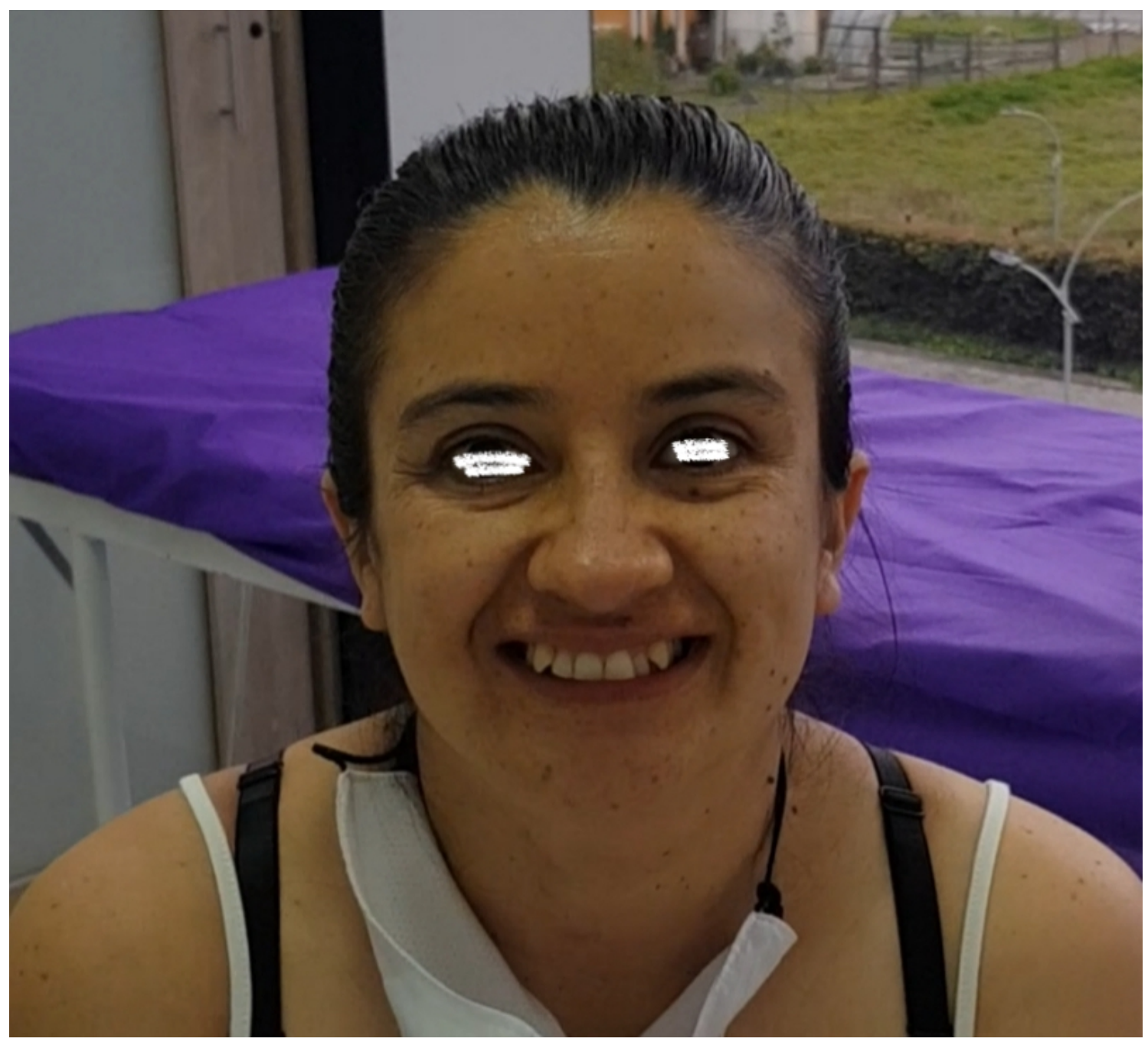

Fotografia junio 13. Recuperacion completa del.100\% de los signos de la parálisis facial. Dia 9 de tratamiento NO hay evidencia de parálisis facial Grado 0/6 en escala de House Brackmann 